\title{
IDÉIAS
}

\section{Sistema de carreiras será o maior desafio}

\section{Aluízio Alves}

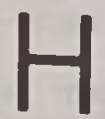

á uma decisão politica de promover profunda reforma na Administraçāo Federal. Desde seus primeiros dias de governo, o Presidente José Sarney proclamou essa preocupaçào. Mas, também, disse claramente - e todas as autoridades envolvidas o têm reiterado - que não se pretende fazer apenas uma colecão de leis e decretos, mas implantar uma nova concepção de administraçào pública, moderna, ágil, produtiva, que resgate a máquina do emaranhado legislativo adotado no último meio século, dos erros e distorçōes acumulados sem nenhum critério, do descrédito a que se submetem os órgãos públicos, pela inoperảncia, pela lentidão de sua operação, pelo arbitrio e vários tipos de favoritismo que dominaram os regimes de pessoal.

Nảo queremos dizer que está tudo errado e que a Nova República vai fazer uma administração modelar.

Aplaudimos quantos esforços foram realizados, sobretudo, a partir de 1936, precisamente há 50 anos, hoje, pela lei no 284 , de 28 de outubro de 1936. Reconhecemos os progressos alcançados, em cada época, pela reforma de 1939, da qual resultou a criaçào do DASP, e pela reforma de 1967, com o Decreto-lei 200, ambas outorgadas pelo Poder Executivo, sem a participaçāo nem das representações dos funcionários e de entidades civis da sociedade, nem dos representantes do povo, através do Congresso Nacional.

O Presidente Sarney recomendou que todas as reivindicaçōes das classes interessadas fossem exami-

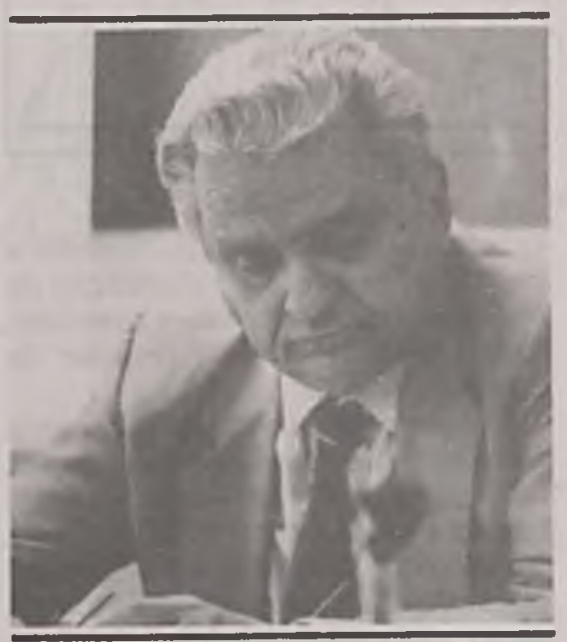

nadas, e o foram, em 1986, através da Comissão Geral da Reforma Administrativa, onde se assentam, desde a primeira hora, os representantes das duas principais entidades de funcionários, e das câmaras técnicas das quais participam representantes de outras entidades. $E$, ressalvados os casos da competência exclusiva do Executivo, todas as propostas terào a discussão e a soberana decisão do Poder Legislativo.

$\mathrm{O}$ que nào se pode é estabelecer prazos ao Executivo para decidir sobre problemas juridicos, técnicos, humanos, de enorme complexidade, que envolvem mais de 20 mil unidades de administraçāo, mais de 400 empresas, 1.800 mil funcionários, com regime de direitos diferentes, com quase uma centena de gratificaçōes diferentes, com quase 400 niveis de vencimentos diferentes, num caos cuja correçào nào será

Ministro-Chele da Secretaria de Administração Pública da Presidência da República e presidente do Grupo Executivo da Reforma Administrativa do Governo Federal.

ajudada pelo emocionalismo que certos grupos exploram tentando conduzir o funcionalismo federal não a soluçōes de seu interesse, mas, as do interesse de lideranças pessoais ou grupos politicos radicais. triz:

O Governo Sarney tem uma dire-

Quer modernizar a administraçāo. Vai fazè-lo.

Quer melhorar a produtividade do serviço público. Vai fazè-lo.

Quer tornar o serviço público transparente e fiscalizado pela sociedade. Vai fazè-lo.

Quer dar ao funcionário regime juridico apropriado, sistema de carreiras baseado no mérito, instrumentos de formação e treinamento que ajudem o progresso de cada um. Vai fazè-lo.

Quer a colaboraçāo da sociedade, das entidades de classe, no exame aplicado e apaixonadu das alternativas viàveis. Espera consegui-lo.

Confia no patriotismo com que o Congresso Nacional examinará as propostas, sem injunçōes descabidas de interesses demagógicos e imediatistas. Nào tem dúvidas de que isto ocorrerá."

O Grupo Executivo de Reformas da Administração Pública GERAP -, iniciou o seu trabalho. propondo à decisão do Governo a reformulação dos primeiros órgãos. Prosseguirá nessa tarefa complexa, vencendo a inércia, as resisténcias. Em que prazo concluira esse trabalho? Não sabemos. Sabemos, apenas, que será no prazo mais rápido em que as pressōes de rapidez não prejudiquem o exame profundo das questões e a decisão do interesse público.

Entre as matérias de mais dificil solução é a que se refere à instituição do sistema de carreiras. Porque vai en- 


\section{IDÉIAS}

volver milhares de funcionàrios com situações as mais dispares. Porque vai exigir a sua adequaçào às estruturas. Porque vai mudar filosofia e prática erroneamente adotadas há meio século.

Sim, há meio século o Serviço Público Federal ensaia procedimentos e experimenta caminhos para transformar seus recursos humanos em instrumento de maior racionalidade e operosidade administrativa.

A constante desses ensaios tem sido a tentativa de estabelecer modelos de classificação de cargos, acompanhados ou não de prescriçōes normativas tendentes a assegurar sua dinâmica, normas que, naturalmente, se basearam nas concepçōes dos modelos adotados.

Mentores e autores desses ensaios, que visaram dotar o Serviço Público Federal de uma administração de pessoal moderna e modernizante, partiram todos do ponto considerado básico na doutrina que informa a referida área - a classificação de cargos, mas incidiram sempre no mesmo equivoco.

$\mathrm{O}$ equivoco, ao qual se podem imputar senão todos pelo menos uma parte considerável das inadequaçōes, dos erros e dos fracassos na administração de recursos humanos e, por conseqüência, na administraçào pública, tem consistido em:

a) considerar a classificaçào dos cargos desvinculada das estruturas organizacionais e sua hierarquia:

b) gerar com isso uma classificação não dos cargos, mas dos seus eventuais ocupantes; $\mathrm{c}$

c) instituir um pseudo-sistema de administração pessoal, cujo artificialismo, além de impossibilitar qualquer esforço para imprimir-lhe racionalidade e objetividade, $c$ diretamente responsável pelo caos reinante na área.

Eis porque qualquer reforma que se queira iniciar no sistema de recursos humanos do Serviço Público Federal terá, necessariamente, de romper com concepçóes e esquemas equivocados, substituindo-os por um conceito integrado de administraçào de pessoal que, partinde da classificação dos cargos reais existentes na estrutura hierárquica da organização administrativa, se constitua em instrumento de uma administração pública eficiente e eficaz e ofereça aos servidores publicos a perspectiva de profissionalização com acesso aos

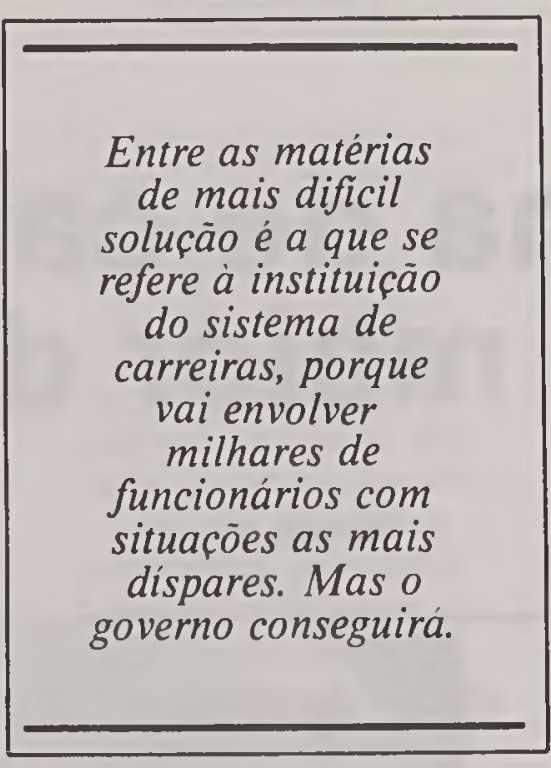

cargos de direçào, assessoramento e chefia, a garantia da valorização da classe e, especialmente, a oportunidade de reaver o auto-respeito da categoria social.

A resposta que se propōe para alcançar csse duplo propósito é a instituição do Sistema de Carreiras, que terá como objetivos:

1 - criar quadros dirigentes especialmente formados e aperfeiçoados para assegurar à Administração maior eficácia, continuidade e condiçōes para a promoção de mudanças e reformas modernizadoras;

2 - estabelecer, em caráter permanente. programas de formaçāo, aperfeiçoamento e de outras modalidades, sempre em nivel de excelência: tais programas visarão a capacitar e manter atualizados os atuais e os futuros funcionarios para ingressarem e se desenvolverem nos referidos quadros; e

3 -garantir aos funcionarios que ingressarem nas carreiras por essa forma e mediante processos seletivos competitivos, o acesso aos cargos de direção, de assessoramento, de chefía e assistência, sempre tomando por base sua capacitação prévia nos programas definidos pelos órgãos próprios do Sistema.

O Sistema de Carreiras é, em essência, uma classificação de cargos, mas uma classificação que se diferencia tambèm em essência das formas que 0 antecederam pelos seguintes aspectos:

1 - parte da análise das estruturas organizacionais onde existem e são identificados os cargos;
2 - inclui na classificação os cargos de direção, de assessoramento, de chefia e assistencia correspondentes às linhas hierárquicas das atividades especificas ou gerais desenvolvidas nas estruturas das organizações;

3 -estabelece nitida separaçāo entre o cargo - pertencente à estrutura e que constitui fenômeno decorrente da divisão do trabalho - e o ocupante, cuja situação é sempre transitória em relação ao cargo;

4 - demanda processo de formação e aperfeiçoamento continuos, bem como de avaliação sistemática a que devem estar submetidos os candidatos ao exercício dos cargos, especialmente os da linha hierárquica.

Esses aspectos representam as premissas em que repousa o Sistema de Carreira e indicam seus componentes necessarios e interdependentes, para os quais devem ser orientadas e desenvolvidas, simultaneamente, as decisóes e ações do Governo, capazes de dar-lhe condiçōes de funcionamento.

Destarte, fica evidente que o Sistema de Carreiras pretende inaugurar uma nova fase no Serviço Público Civil, elevando os recursos humanos à categoria que ocupam na administração dos paises mais desenvolvidos, cujo crescimento e liderança no mundo hodierno se devem, em grande parte, à preparaçào e ao aproveitamento útil desses recursos.

Com efeito, o novel Sistema não deve nem pode ser encarado como um plano de classificação de cargos no sentido das classifir,açóes anteriores, onde o cargo terminou por ser confundido com o ocupante; a classe passou a ser mero simbolo de antigüidade e diferença salarial; e a categoria funcional nada mais é que simples abstração nominal para designar agrupamentos profissionais.

Assim, è preciso compreender claramente, de uma vez por todas, que cargo è unidade de organização existente numa dada estrutura. Sua presença se legitima enquanto corresponde a atividades e tarefas reais no tempo e no espaço; preexiste e subsiste virtualmente ao ocupante, embora seja este que lhe empresta vida e o dinamiza.

Infere-se dai a necessidade de formar, aperfeiçoar, treinar e reciclar, num processo de educação permanente, os funcionários que ocuparão os cargos da organização administrativa. O programa de aperfeiçoamento 


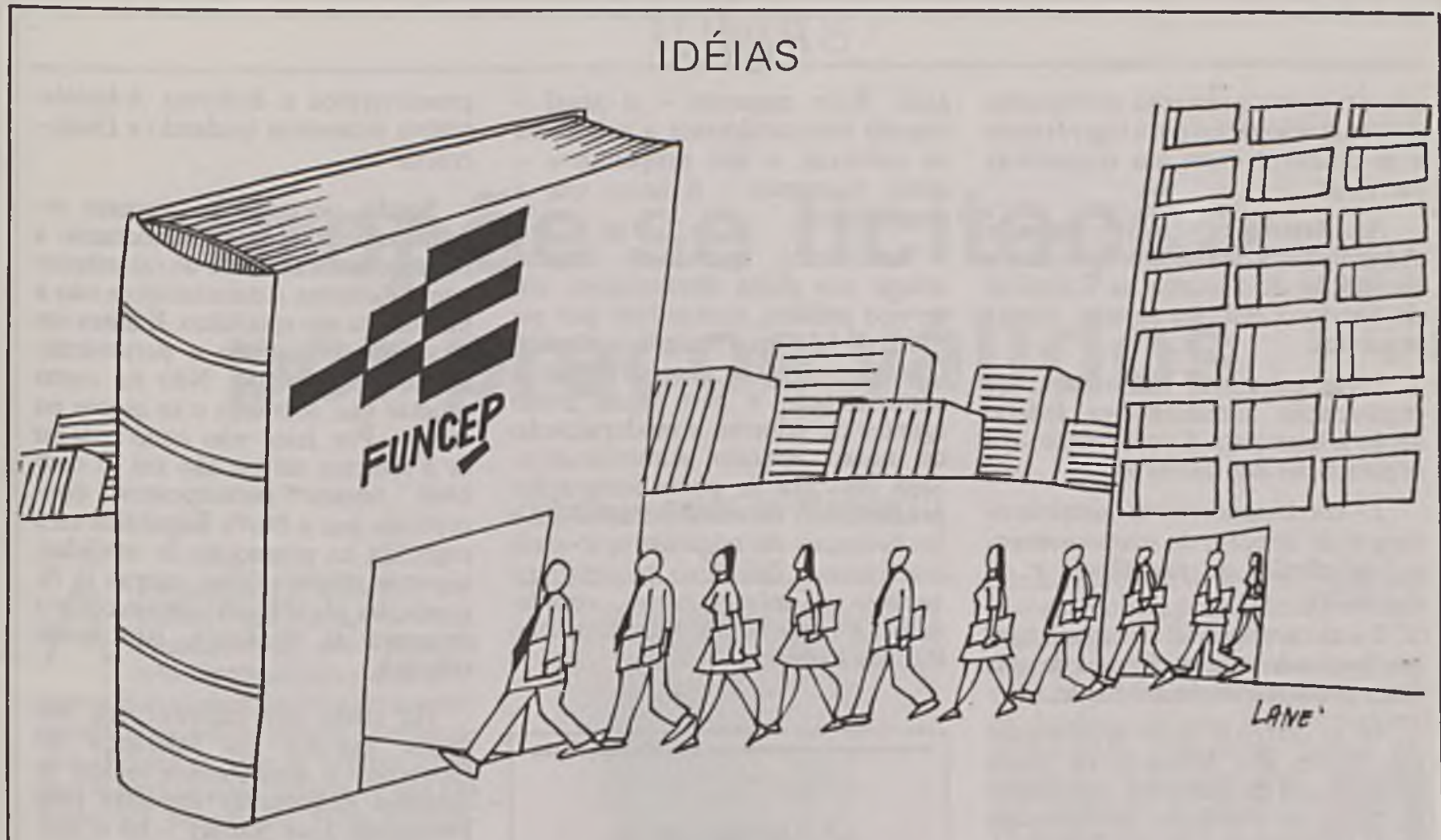

assegura, por um lado, o desempenho produtivo e eficaz do Serviço Público Federal e, por outro, propicia aos funcionários a instrumentalidade de conhecimentos, técnicas, métodos e comportamentos indispensáveis ao desempenho efetivo dos cargos da estrutura, dentro do respectivo horizonte profissional identificado para sua carreira.

O Sistema de Carreiras organizase e opera com base na percepçào e compreensão dessa dinámica dicotômica, porém integrada. O Sistema de Carreiras é, de fato, sinónimo de profissionalização. Flui num processo de educação continua, onde conhecimento e experiència se complementam, se reestruturam e se reforcam, propiciando ao individuo capacitação e amadurecimento para ascender aos mais altos niveis profissionais da estrutura na qual atua. incluidos ai a direção, o assessoramento e a chefia de atividades e de grupos, dentro de suas carreiras.

Embora as pessoas que hoje ingressam no Serviço Público possuam formaçāo de diferentes graus concedidos pelo sistema de ensino formal, nào estão, de regra, preparadas para o exercicio da função pública; esta requer um tipo de conhecimento, uma atitude, enfim, uma postura que nāo se encontra necessariamente em pro- fissionais habilitados para atuarem no contexto social mais amplo.

Se isso ocorre, de modo geral, com as profissōes consideradas do ponto de vista estrito de seus campos especializados, que dizer quando se visualizam essas profissōes em termos de gerenciamento das atividades que Ihes correspondem no Servico Público Federal.

\section{Há necessidade de} formar, aperfeicoar. treinar e reciclar, num processo de educacão permanente, os funcionários que ocuparāo os cargos da organização administrativa. 0 programa assegura o desempenho eficaz do Serviço Público.
Como regra, é evidente que os profissionais especialistas não têm de forma sistematizada informaçōes sobre gerēncia. Exceção à regra são os administradores formados pelas escolas de administração que recebem ensinamentos gerenciais e, portanto, estão, em principio, municiados para o gerenciamento das atividades relativas à administração-meio, isto é, as atividades tipicas dos Departamentos de Administração.

Observa-se, então, a existência de uma lacuna de preparação sistemática para a gerência entre os profissionais especializados do Serviço Público Federal que são, em última análise, os responsáveis pela execução das atividades-fím do Estado e pela consecução eficaz dos seus objetivos nas diversas áreas em que tais atividades se exercem. Em outras palavras, a saúde, a educaçāo, o transporte, a agricultura etc.

Dai a necessidade de instituir-se o Sistema de Carreiras que apresenta como caracteristica fundamental a integração entre as atividades especificas dos diferentes setores da Administração, seja a administração geral seja a administração-fim, consideradas nos diversos niveis hierárquicos, a organização e classificação dos funcionários em carreiras para exercerem tais atividades, e a forma- 


\section{IDÉIAS}

çào e o aperfeiçoamento permanente desses funcionários para ingressarem e se desenvolverem nas respectivas carreiras.

As Diretrizes que a Secretaria de Administração Pública propōe para a instituição do Sistema de Carreiras do Serviço Civil, em síntese, são as seguintes:

1 - as estruturas hierárquicas da organizaçào administrativa federal serão a base para a constituição e a organizaçào das carreiras;

2 - corresponderão às carreiras os cargos de direção, de assessoramento, de chefia, de assistència e de execução;

3 - as carreiras serão organizadas em função de uma ou de mais de uma linha profissional de atividade:

4 - as carreiras serào escalonadas em classes que refletirão os niveis hierárquicos da estrutura, vinculados às linhas de atividades profissionais de nivel superior e de nivel médio;

5 - a carreira do funcionário ocorrerá à medida em que ele se desenvolva dentro de uma linha profissional em seus diferentes niveis hierárquicos;

6 - o ingresso e o desenvolvimento do funcionário na carreira far-se-á sempre por mérito:

7 - o mérito será comprovado em concurso público e posterior formaçà, no caso de ingresso, e por programas de formaço e aperfeicoamento, no caso de promoça:

8 - a promoçào implicara scmpre o exercicio de cargo de nivel hierarquico superior aquele en que se encontrava o funcionario:

9-o funcionario que ingressar numa carreira assume o compromisso de cumprir os programas de formaçào c aperfeiçoamento; c

10 - a formaçào c o aperfeiçoamento do funcionário na instrumentalidade gerencial terá caráter obrigatório e geral para todas as carreiras.

Em suma, a instituição do Sistema de Carreiras importa, virtualmente, uma ruptura. Nào uma ruptura que renega o passado. Temos de reconhecer que especialmente a Reforma da década de 40 - iniciada pela Lei 284. de 1963 -produziu resultados ate hoje marcantes. O sistema que se propóe substituirá o esquema da classificaçào de cargos que vigora há cinqüienta anos. Esse esquema - o atual impede estruturalmente a existência de carreiras; o que propomos é assim o cremos - o único que a possibilitará.

Antevemos, quando o sistema atingir sua plena implantação, um serviço público, comandado por estratos de liderança realmente capacitadas para gerir superiormente a administração e para atuar como agentes de reforma e modernização de nosso aparato administrativo. Será uma era de plena integração: profissionais da administraçäo-fim e profissionais da administração-meio em franco e definitivo processo associado de planejamento, coordenação e controle da Administraçāo Pública Federal.

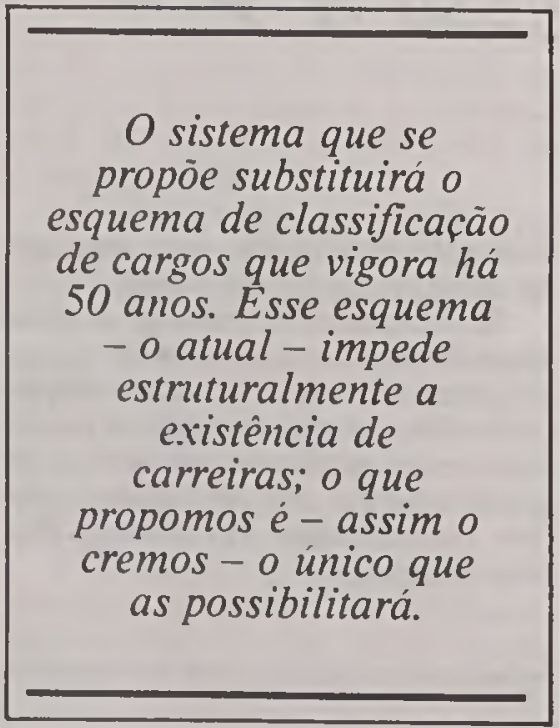

O compromisso solenemente assumido pela Nova República-o de promover a reforma administrativa do Serviço Publico Federal - decorre não apenas de um imperativo conjuntural. E que nutrimos a mais profunda conviccão de que as reformas são em verdade o apanágio das democracias.

O regime democrático caracteriza-se, nesse particular, por ser essencialmente reformista. Em verdade, os democratas tèm consciència de que suas instituiçòes nāo sảo perfeitas. Ao contrário das sociedades fechadas nào democráticas, que se consideram perfeitas e acabadas, a sociedade aberta, isto é, a democracia, sabe que se rejuvenesce e moderniza à medida em que aperfeiçoa e reforma as suas instituiçòes. Assim, ao promovermos a Reforma Administrativa estaremos ajudando a Democracia.

Sendo, portanto, o processo reformista intrínseco a Democracia, a conseqüência é termos de reconhecer que a Reforma Administrativa nảo é um fato ou ato episódico. E antes um processo continuado e perseverantemente sustentado. Não há como esperar que aconteca e se esgote no tempo. Por isso, nāo cabe indagar se a reforma sai ou nào sai. $E$ com base nesses pressupostos conceptuais que a Nova República está engajada na promoção de medidas, algumas preparatórias, outras já de execução, objetivando desenvolver o processo de mudança, isto é, de reforma.

Há ainda que registrar que nos vários estratos de liderança do Governo - e aqui cumpre realçar as decisỏes firmemente tomadas pelo Presidente José Sarney - há o sentimento unânime de que a Nova República tem presente o carater de desafio que lhe é lançado pela questão da reforma administrativa. E conhecida a corrente de opinião que adota a tese de que paradoxalmente no Brasil, nos regimes de franquias democráticas, como as que caracterizam a Nova República, as reformas administrativas enfrentam óbices e dificuldades que praticamente as inviabilizam. Afirmam, em contraste, que os regimes fortes realizam reformas confortavelmente. Costumam os adeptos dessa tese referir os exemplos da história administrativa do Governo Federal que registra como reformas efetivas a da decada de 40 , capitaneada pelo antigo DASP, e a do Decreto-lei 200/67, ambas realizadas em periodos de regime autoritário.

A Nova República aceita o desafio. Estamos engajados no processo de reforma, vamos perseverar nesse propósito e nảo pouparemos esforços e energias. Nào temos dúvidas de que - clima da Nova República - o da democratizaçào - vai ensejar as melhores condiçōes para os nossos objetivos de recuperar a administraçào pública brasileira. Afinal de contas a mobilização nacional que nos abriu promissoras e claras avenidas em direção à plenitude democrática haverá de constituir-se em valoroso bastião para novas conquistas desta Nova República. 